\title{
Effect of gossypol on testicular blood flow and testosterone production in rats
}

\author{
J. M. Wang, C. H. Gu, Z. M. Qian* and G. W. Jing \\ Department of Pharmacology, Nanjing Institute of Materia Medica, 26 Ma Jia Jie, Nanjing, \\ People's Republic of China
}

\begin{abstract}
Summary. Rats were treated with highly purified gossypol acetic acid at doses of 15 or $30 \mathrm{mg} / \mathrm{kg} \mathrm{day}^{-1}$ for 6 weeks to produce an effect on spermatogenesis as shown by reduced sperm motility and increased sperm malformation rates. The treated rats did not differ from the controls in the body weight growth curves and reproductive organ weights. When stimulated with hCG, testicular blood flow was increased in the low dose group; the testosterone concentrations in peripheral and testicular venous blood were also increased to a greater extent than those of the control group. No difference was found between the high dose and control groups in testicular blood flow or testosterone concentrations. The morphology of the Leydig cells was apparently normal, although some degenerative changes in the germinal epithelium were observed in the high dose group. Therefore, there is no evidence in our experiment to show any anti-androgenic effect following 6-week treatment of gossypol in rats, even at the dose of $30 \mathrm{mg} / \mathrm{kg} \mathrm{day}^{-1}$.
\end{abstract}

\section{Introduction}

The antispermatogenic action of gossypol is well known, but the nature of the functional changes induced in the Leydig cell remains controversial. Despite the earlier encouraging reports (National Coordinating Group on Male Antifertility Agents, 1978; Xue, 1980) that gossypol was free from any anti-androgenic effect, contradictory information has appeared (Hadley, Lin \& Dym, 1981; Liang, Pang, Dong \& Dai, 1981; Lin, Murono, Osterman, Nankin \& Coulson, 1981). Previous studies of the effect of gossypol on the endocrinological function of the testis did not investigate changes in testicular blood flow which may affect the local production of testosterone (Hadley et al., 1981; Lin et al., 1981; Chang, Gu \& Tsong, 1982). Attempts have been made (Gafvels, Bergh, Damber, Selstam \& Wang, 1981) to study testicular blood flow and plasma testosterone concentrations in rats treated with gossypol, but because the antifertility effect of the drug was not checked in the same study this problem needs further elucidation. The present experiment was undertaken to relate changes in hormone secretion to testicular blood flow in rats treated with an antispermatogenic dose of gossypol.

\section{Materials and Methods}

Animals. Adult male rats of the pure Wistar strain (derived from the Institute of Materia Medica, Chinese Academy of Medical Sciences, Beijing) and weighing $274 \pm 22 \mathrm{~g}$ were kept at a

\footnotetext{
* Present address: Jiangsu Institute of Traditional Chinese Medicine, Nanjing, People's Republic of China.
} 
temperature of $15-20^{\circ} \mathrm{C}$ with $12 \mathrm{~h}$ light/ $24 \mathrm{~h}$ (lights on $06: 00-18: 00 \mathrm{~h}$ ). Food and water were always available. Food was prepared freshly according to a standard recipe with some modifications (Wang et al., 1981).

Initially, 60 rats were allocated at random to 3 groups ( 20 rats/group). The rats in Groups 2 and 3 were given gossypol acetic acid (purified at our Institute to be $99.71 \%$ pure as verified by u.v. spectrophotometry and thin-layer chromatography) in suspension with carboxymethyl cellulose (CMC), $1 \mathrm{ml}$ containing $3 \mathrm{mg}$ gossypol in $1 \% \mathrm{CMC}$ solution, by oral feeding in a daily dosage of 15 (Group 2) or 30 (Group 3) $\mathrm{mg} / \mathrm{kg}$. The control rats in Group 1 were fed with CMC solution only. Treatment was continued for 6 weeks. The actual numbers of rats eventually available for study were less than 20 in each group $(19,17,16$ in Groups 1,2 and 3, respectively) because of the loss of animals during the course of treatment due to misintubation. A fresh suspension of the drug was made every morning just before application. Roughly half of the animals in each group (8-11) were injected subcutaneously with 100 i.u. hCG (Chorulon: Intervet, Cambridge, U.K.) 2 h before the measurements of blood flow and the collection of blood samples for analysis.

Testicular blood flow and hormone secretion. Testicular blood flow was measured by a microsphere technique (Damber \& Janson, 1977; Jaffe \& Free, 1979; Setchell \& Sharpe, 1981). For this purpose the rats were anaesthetized with pentobarbitone sodium (Sagatal: May \& Baker, Essex, U.K.; $50 \mathrm{mg} / \mathrm{kg}$ i.p.). Two polyethylene catheters $(0.8 \mathrm{~mm}$ o.d., $0.5 \mathrm{~mm}$ i.d.; Dural Plastics, New South Wales, Australia) were introduced; one was inserted through the left carotid artery with its tip in the aortic arch, and the other was placed in a femoral artery. The animal was then heparinized ( 500 units injected intra-arterially) and blood was withdrawn from the femoral artery with a syringe withdrawal pump at a constant speed of $257 \mu \mathrm{l} / \mathrm{min}$. Sampling was started $15 \mathrm{sec}$ before the microspheres labelled with ${ }^{57} \mathrm{Co}$ (New England Nuclear, Dreiech, West Germany; 150000 microspheres containing $5 \mu \mathrm{Ci}$ in $0.1 \mathrm{ml} 0.154 \mathrm{M}-\mathrm{NaCl}$, diluted and thoroughly mixed by vortexing) were injected into the aortic arch. A reference blood sample from the femoral artery was collected for 3 min after the injection, and then blood samples were taken from both testicular veins, as described by Main $\&$ Setchell (1980). Briefly, the superficial vein on the testicular wall was punctured gently with a sharp injection needle, so that venous blood could be collected into a plastic vial by means of a glass capillary. Peripheral blood was taken from the carotid artery through the indwelling catheter. After killing the animal by opening the chest, both testes, epididymides and kidneys were removed, weighed and the radioactivity in the femoral artery blood sample and in these organs was measured with a gamma-spectrometer (FT-603, Beijing). Mixing of spheres was confirmed if the two kidneys gave values within $15 \%$ of one another. Blood flows were calculated in $\mu 1 / \mathrm{min}$ by dividing the amount of radioactivity in the testis by that in the femoral artery blood sample, multiplied by the rate of blood sampling.

Both testes were then decapsulated, the cells were dispersed by forcing the parenchyma through a No. 9 injection needle and a fluid fraction consisting of a mixture of tubular and interstitial fluid was separated from the cells by centrifugation.

At autopsy one testis of some animals ( 6 animals in each group) was fixed by perfusion with saline $(0 \cdot 154 \mathrm{M}-\mathrm{NaCl})$ followed by Bouin's fluid into the testicular artery and then embedded in paraffin wax. Sections were made and stained with haematoxylin and eosin.

For all animals the tail of the epididymis was removed, cut with fine scissors to release the spermatozoa, and then the whole mass was placed in Tyrode's solution (Perry, 1970). A drop of the suspension thus formed was examined by bright-field light microscopy for sperm motility and malformation rates. The results of mating fertility tests closely coincided with the corresponding changes of sperm motility and malformation rates in the same animals: a zero pregnancy rate was obtained when the sperm motility rate was reduced from $94 \pm 0.74$ (mean \pm s.e.m.) to $2.4 \pm 1.5 \%$ (W. H. Wang \& M. Cai, unpublished data).

Plasma was separated from testicular venous and arterial blood samples and stored at $-20^{\circ} \mathrm{C}$ until analysed for testosterone. 
Radioimmunoassay. Plasma testosterone concentrations were determined by radioimmunoassay (Research Laboratory of Endocrinology, Second Shanghai Medical College, 1978). The testosterone antiserum was raised against testosterone-3-BSA. The percentage cross-reaction to $5 \alpha$-dihydrotestosterone was $50 \%$. However, Sephadex-LH- 20 column chromatography was omitted because rat blood has been shown to contain a negligible amount of $5 \alpha$-dihydrotestosterone (Falvo \& Nalbandov, 1974). The testosterone assay had an intra-assay coefficient of variation of $6.9 \%$ and an inter-assay coefficient of variation of $18.4 \%$. The sensitivity of the standard curve was $10 \mathrm{pg}$.

Testosterone production was calculated by multiplying the difference in testosterone concentrations between testicular venous and arterial plasma by plasma flow which was obtained by multiplying blood flow by $(1-$ haematocrit value $)$. The haematocrit value was presumed to be $45 \%$ (see Mather \& Rushmer, 1979).

Statistics. The data were expressed as mean \pm s.e.m. and assessed by one-way analysis of variance as well as Student's $t$ test for comparison of mean values between the control and the treated groups.

\section{Fertility}

\section{Results}

There was a clear antispermatogenic effect of treatment in rats in Groups 2 and 3: the sperm motility rate was reduced from $94.0 \pm 0.5 \%$ in Group 1 to $1.2 \pm 0.8 \%$ in Group 2 and $0 \%$ in Group 3 while the malformation rate was raised from $5 \cdot 0 \pm 0.5 \%$ in Group 1 to $40.0 \pm 17 \cdot 0 \%$ in Group 2 and $45.0 \pm 9.0 \%$ in Group 3 .

\section{Body and organ weights}

The growth rate curves of the 3 groups of rats were similar (Text-fig. 1) and there was no obvious effect of gossypol during the 6 weeks of treatment.

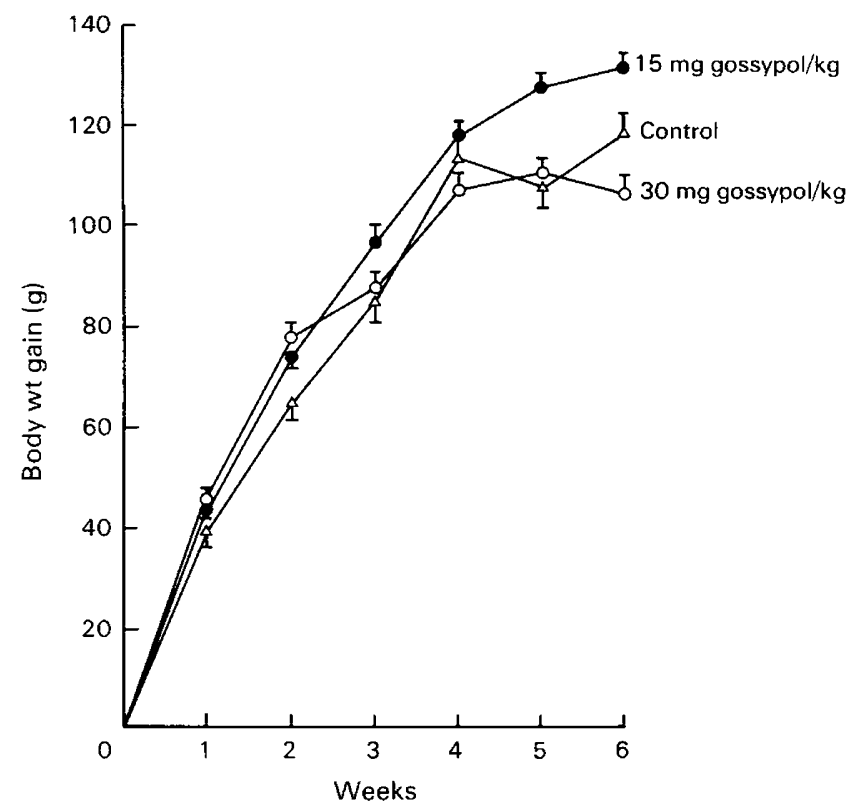

Text-fig. 1. Body weight changes (mean \pm s.e.m.) in rats in Groups 1 (control), 2 (15 mg gossypol $\left./ \mathrm{kg} \mathrm{day}^{-1}\right)$ and $3\left(30 \mathrm{mg}\right.$ gossypol $\left./ \mathrm{kg} \mathrm{day}^{-1}\right)$ during the 6-week treatment. 


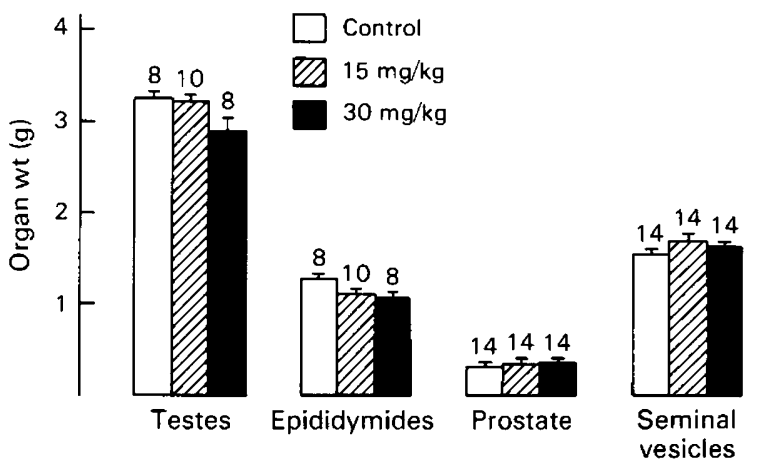

Text-fig. 2. The reproductive organ weights in rats in Groups 1,2 and 3 after treatment with gossypol for 6 weeks. Values are mean \pm s.e.m. for the no. indicated above each column.

There were no significant differences in the weights of testes, epididymides, prostate and seminal vesicle glands (Text-fig. 2), although the average weights of testes in Group 3 dropped slightly because of the occurrence of testicular atrophy in 2 rats.

\section{Blood flow}

The mean \pm s.e.m. testicular blood flow in Group 1 rats was $344 \pm 36 \mu 1 / \mathrm{min} \mathrm{g}$ tissue ${ }^{-1}$ which is in agreement with values reported in the literature (Damber \& Janson, 1977; Gafvels et al., 1981). There was no significant variation in testicular blood flow in Groups 2 and 3 (Text-fig. 3). After injection of hCG blood flows to the testes and epididymides were increased in Group $2(P<0.05)$, but not in Group 3, while surprisingly a reduction of testicular blood flow was observed in Group 1 (Text-fig. 3).

(a) Testis

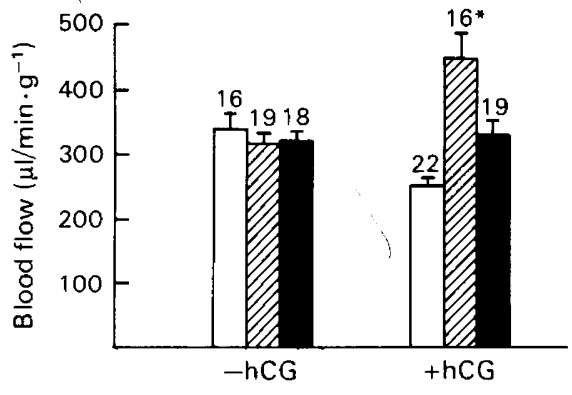

(b) Epididymis

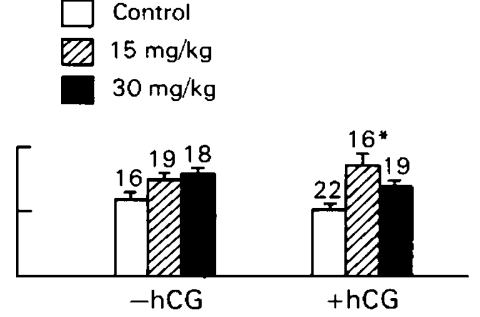

Text-fig. 3. Comparison of blood flows to the epididymis and testis before and after stimulation of rats in Groups 1, 2 and 3 with hCG. Values are mean \pm s.e.m. for the no. indicated above each column. ${ }^{*} P<0.05$ (analysis of variance).

\section{Testosterone production}

There were no consistent changes in the concentration of testosterone in the peripheral blood before stimulation with hCG in Groups 2 and 3 compared with Group 1 (Text-fig. 4). Treatment with hCG caused a marked increase in the concentration of plasma testosterone in all groups; the degree of response was similar in Groups 1 and 3, but the testosterone level was increased to a greater extent in Group 2 than in Group $1(P<0.05)$. 

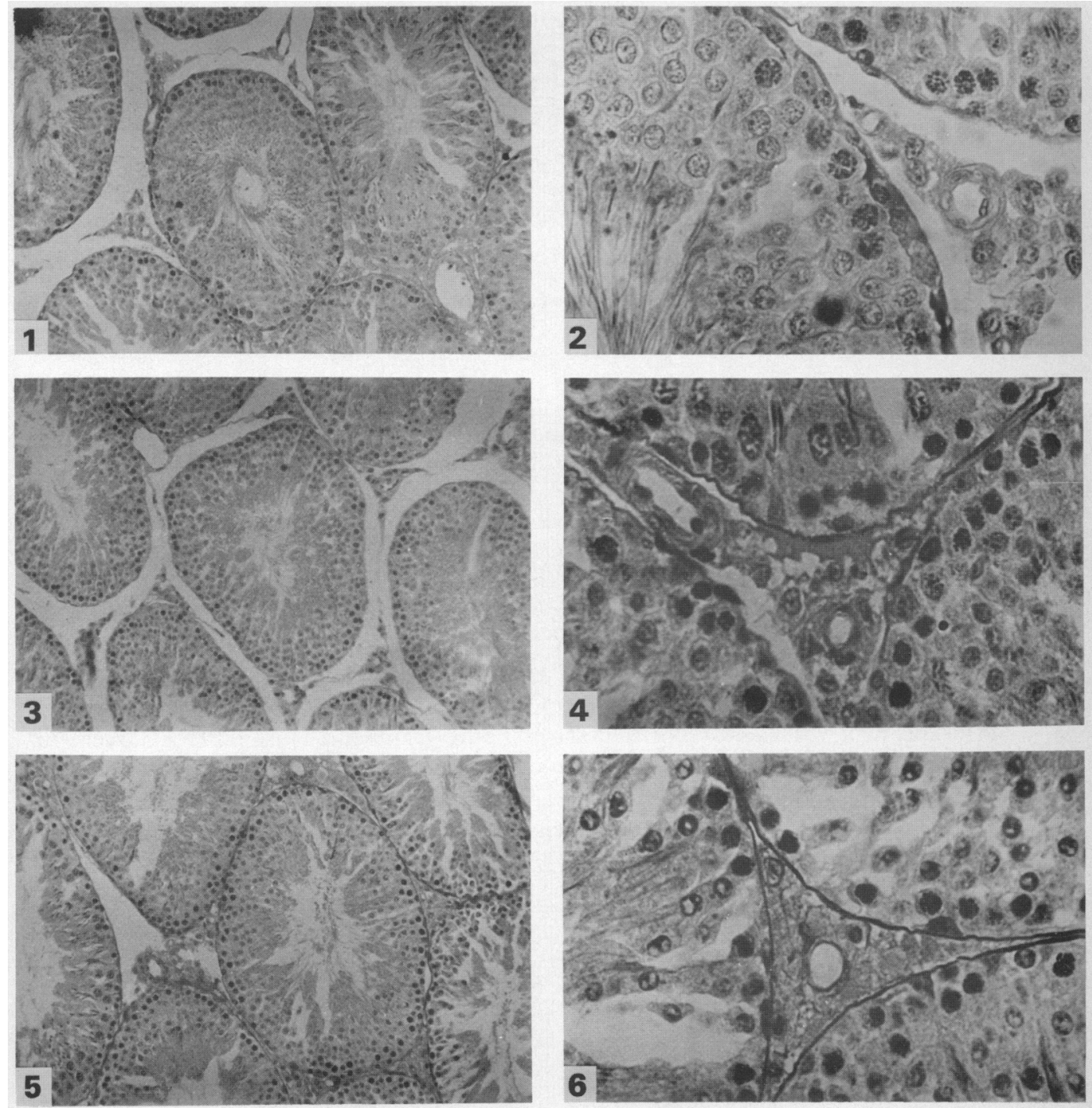

Photomicrographs of testicular tissues from control rats and rats treated with gossypol for 6 weeks at low $\left(15 \mathrm{mg} / \mathrm{kg} \mathrm{day}^{-1}\right)$ or high $\left(30 \mathrm{mg} / \mathrm{kg} \mathrm{day}^{-1}\right)$ doses.

Fig. 1. Testis of a control rat showing normal structure of the germinal epithelium in which spermatogonia, primary spermatocytes, spermatids and mature spermatozoa are seen. H\&E, $\times 190$

Fig. 2. Higher magnification of Fig. 1. $\times 760$.

Fig. 3. Testis of a rat treated with the low dose of gossypol. The various cellular components of the germinal epithelium and the Leydig cells are virtually normal in appearance. $\mathrm{H} \& \mathrm{E}, \times 190$.

Fig. 4. Higher magnification of Fig. 3. $\times 760$.

Fig. 5. Testis of a rat treated with high dose of gossypol in which vacuolation and karyorrhexis of spermatids as well as pycnosis of primary spermatocytes are clearly seen. The morphology of the Sertoli cells and Leydig cells is apparently normal. H\&E, $\times 190$.

Fig. 6. Higher magnification of Fig. 5. $\times 760$. 

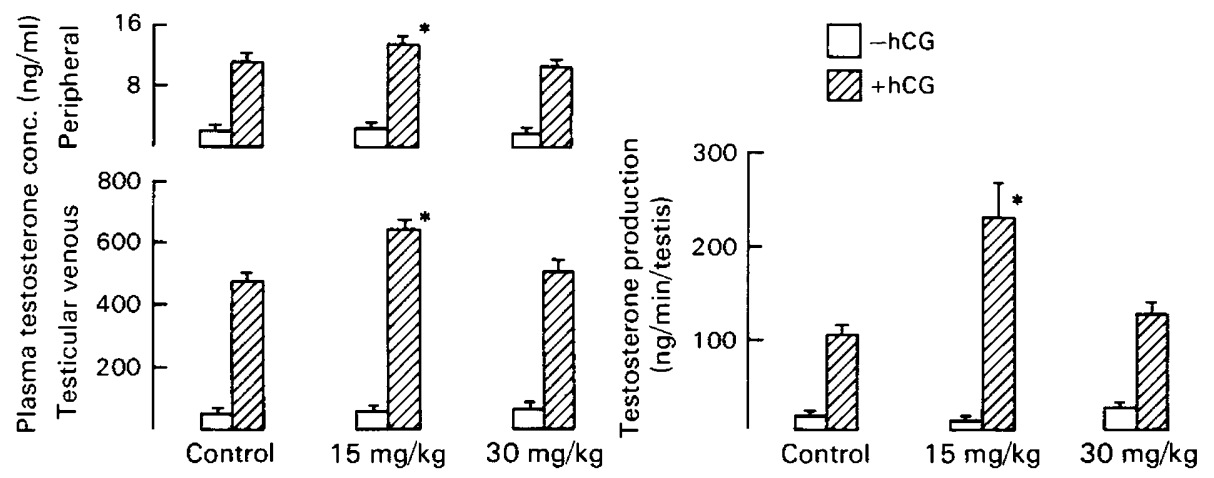

Text-fig. 4. Comparison of testosterone concentrations in peripheral and testicular venous plasma and testosterone production before and after stimulation with hCG in rats in Groups 1 , 2 and 3. Values are mean \pm s.e.m. ${ }^{*} P<0.05$ (Student's $t$ test).

A similar pattern was found for the concentration of testosterone in blood from the testicular vein (Text-fig. 4). Testosterone production by the testis after stimulation with hCG was therefore higher in Group 2 than in Groups 1 and 3 and there was virtually no difference in the unstimulated production of testosterone between these 3 groups (Text-fig. 4).

The testosterone concentration in the testicular fluid showed a picture different from that of the peripheral arterial and testicular venous blood in that stimulation by hCG led to a greater increase in Group $3(63 \pm 9 \mathrm{ng} / \mathrm{ml}, \mathrm{N}=13$, and $646 \pm 186 \mathrm{ng} / \mathrm{ml}, \mathrm{N}=9)$ than in Groups $1(63 \pm 13 \mathrm{ng} / \mathrm{ml}, \mathrm{N}$ $=14$, and $420 \pm 31 \mathrm{ng} / \mathrm{ml}, \mathrm{N}=17)$ and $2(63 \pm 7 \mathrm{ng} / \mathrm{ml}, \mathrm{N}=16$, and $471 \pm 46 \mathrm{ng} / \mathrm{ml}, \mathrm{N}=9)$. However, these differences were not statistically significant (by Student's $t$ test) because of the variation in response of individual rats, as 2 rats in this group had atrophied testes which showed values as high as $1000-2000 \mathrm{ng} / \mathrm{ml}$ after hCG.

\section{Morphology}

The structure of the seminiferous epithelium in Group 2 rats appeared to be unchanged from that of the control animals (Pl. 1, Figs 1-4). In Group 3 some seminiferous tubules contained spermatids that showed pycnosis, thickening of the nuclear membrane and vacuolation. Aggregation of nuclear chromatin and karyorrhexis were also observed in a small proportion of spermatocytes. However, spermatogonia, Sertoli cells and Leydig cells were apparently normal (P1. 1, Figs 5 \& 6).

\section{Discussion}

It is conceivable that hCG causes an enhancement of steroidogenesis by Leydig cells which in turn may induce an increment of testicular blood flow accordingly because of the metabolic needs. Therefore, the increase of testicular blood flow is usually preceded by the activation of steroidogenesis under the influence of hCG. Setchell \& Sharpe (1981) as well as Damber, Selstam \& Wang (1981) found that testicular blood flow was increased only 16-24 h later following injection of hCG, while an early response in blood flow to hCG was insignificant. This is in agreement with our finding that testicular blood flow is virtually unchanged $2 \mathrm{~h}$ after treatment with hCG, although steroidogenesis has already been markedly activated in such circumstances. The slight reduction of testicular blood flow after stimulation by hCG observed in the control group is difficult to explain at present. However, the enhanced steroidogenic response to hCG associated with the increased hCG-induced response in blood flow to the testis and epididymis in the rats treated with a low dose 
of gossypol (Group 2) is evidence that gossypol may stimulate Leydig cell function when a low antispermatogenic dosage is used.

Since the plasma testosterone concentration in the rats treated with $30 \mathrm{mg}$ gossypol/ $\mathrm{kg}$ (Group 3) did not differ from that of the control group and the organ weights showed no reduction, there is no evidence of an antiandrogenic effect even under the influence of a very high antispermatogenic dose of gossypol. In these respects our experimental results support earlier reports from China that gossypol does not affect libido, morphology of Leydig cells, weights of androgen-dependent sex organs or plasma testosterone levels.

However, differences exist in the results from various laboratories. For instance, Hadley et al. (1981) as well as Chang et al. (1982) found a reduction of serum testosterone and LH concentrations in rats treated with $30 \mathrm{mg}$ gossypol $/ \mathrm{kg} \mathrm{day}^{-1}$ for 5 weeks, while Liang et al. (1981) reported a marked reduction of serum testosterone concentration without a corresponding change in LH level following a 1 -month treatment with gossypol $\left(17 \mathrm{mg} / \mathrm{kg}\right.$ day $\left.{ }^{-1}\right)$. Lin et al. (1981) treated rats for only 1 week by subcutaneous injection of gossypol oil emulsion and found $50 \%$ reduction of serum testosterone level even at a dose as low as $1 \mathrm{mg} / \mathrm{kg}_{\text {day }}{ }^{-1}$.

At present, therefore, it is difficult to be certain whether and how gossypol affects Leydig cell function. It is understandable that the biological action of gossypol is not only dose-dependent, but also involves many factors. For instance, the purity of the gossypol powder needs to be stressed, as Waller, Fong, Cordell \& Soejarto (1981) claimed that the impurities present may negate the antifertility action of gossypol. Some technical points may also affect the experimental results. The route of subcutaneous injection is now generally abandoned because of local as well as general toxic effects, while improper intubation during oral feeding in the course of treatment may damage the oesophagus or cause other serious consequences.

Therefore, unless the factors involved are strictly controlled, experimental data from different places are difficult to compare on the basis of dosage. In view of our experimental results it seems unlikely that gossypol affects Leydig cell function to any extent when a moderate antispermatogenic dosage is used. It is still not certain whether androgen production is suppressed by long-term medication or with high doses. An abnormal hormonal picture is likely to occur in animals with atrophied testes accompanied by a reduction in testicular blood flow, as observed in a few exceptional cases in Group 3 in the present experiment. As occurs after X-irradiation (Wang, Galil \& Setchell, 1983) and local heating, because blood flow perfusing the testes drops when the tubules atrophy, testosterone production may be decreased due to circulatory stagnation, although the Leydig cells still produce normal amounts of testosterone, causing a local accumulation of steroid in testicular fluid. Further investigation is therefore required for a better understanding of the circulatory and endocrinological changes following a longer period of gossypol treatment.

This investigation received financial support from the Special Programme of Research, Development and Research Training in Human Reproduction, World Health Organization. We thank Tao Lian for valuable assistance, Wu Song-yun for help with the histology, and Dr R. B. Heap for his encouragement and advice during the preparation of this manuscript.

\section{References}

Chang, C.C., Gu, Z.P. \& Tsong, Y.Y. (1982) Studies on gossypol. 1. Toxicity, antifertility and endocrine analysis in male rats. Int. J. Fert. 27, 213-218.

Damber, J.E. \& Janson, P.O. (1977) Methodological aspects of testicular blood flow measurement in rats. Acta physiol. scand. 101, 278-285.

Damber, J.E., Selstam, G. \& Wang, J. (1981) Inhibitory effect of estradiol-17 $\beta$ on human chorionic gonadotropin-induced increment of testicular blood flow and plasma testosterone concentration in rats. Biol. Reprod. 25, 555-559.

Falvo, R.E. \& Nalbandov, A.V. (1974) Radioimmunoassay of peripheral testosterone in males from eight species using a specific antibody without chromatography. Endocrinology 95, 1466-1468.

Gafvels, M., Bergh, A., Damber, J.E., Selstam, G. \& Wang, J. (1981) Testicular blood flow and plasma testosterone in rats treated with gossypol-a pro- 
posed antifertility agent. Acta physiol. scand. 112,6A, Abstr.

Hadley, M.A., Lin, Y.C. \& Dym, M. (1981) Effects of gossypol on the reproductive system of male rats. $J$. Androl. 2, 190-199.

Jaffe, R.A. \& Free, M.J. (1979) The determination of blood flow in reproductive organs. In Animal Models for Research in Contraception and Fertility, pp. 496 509. Ed. N. J. Alexander. Harper \& Row, New York.

Liang, S.X., Pang, S.N., Dong, R.H. \& Dai, R.X. (1981) Radioimmunoassay of serum concentrations of testosterone and LH in male rats administered with gossypol. Acta biol. exp. Sin. 2, 191-197.

Lin, T., Murono, E.P., Osterman, J., Nankin, H.R. \& Coulson, P.B. (1981) Gossypol inhibits testicular steroidogenesis. Fert. Steril. 35, 563-566.

Main, S.J. \& Setchell, B.P. (1980) Responsiveness of the pituitary gland to androgens and of the testis to gonadotrophins following damage to spermatogenesis in rats. $J$. Endocr. 87, 445-454.

Mather, E.C. \& Rushmer, R.A. (1979) Physiological parameters of some species used in reproduction research. In Animal Models for Research in Contraception and Fertility, p. 561. Ed. N. J. Alexander. Harper \& Row, New York.

National Coordinating Group on Male Antifertility Agents (1978) Gossypol-a new antifertility agent for male. Chin. med. J. (Engl.) 4, 417-428.
Perry, W.L.M. (1970) Pharmacological Experiments on Isolated Preparations, p. 153. Churchill Livingstone, Edinburgh.

Research Laboratory of Endocrinology, Second Shanghai Medical College (1978) Radioimmunoassay of plasma testosterone. Zhonghua Yixue Jianyan Zazhi (Chinese Journal of Medical Laboratory Technology) 1, 19-24.

Setchell, B.P. \& Sharpe, R.M. (1981) Effect of injected human chorionic gonadotrophin on capillary permeability, extracellular fluid volume and the flow of lymph and blood in the testes of rats. J. Endocr. 91, 245-254.

Waller, D.P., Fong, H.H.S., Cordell, G.A. \& Soejarto, D.D. (1981) Antifertility effects of gossypol and its impurities on male hamsters. Contraception 23, 653660.

Wang, J., Galil, K.A.A. \& Setchell, B.P. (1983) Changes in testicular blood flow and testosterone production during aspermatogenesis following $\mathrm{X}$-irradiation. $\boldsymbol{J}$. Endocr. 98, 35-46.

Wang, N.T., Gu, W.Q., Yan, L.C., Gu, Z.J., Su, J.M. \& Zhou, H.L. (1981) Study on the recipe of feed for experimental rabbits. Shanghai Chymushouyitongxun (Shanghai Animal Science Bulletin) 2, 64-67.

Xue, S.P. (1980) Studies on the antifertility effect of gossypol, a new contraceptive for males. In Recent Advances in Fertility Regulation, pp. 122-146. Ed. C. F. Chang. S.A. Atar Press, Geneva.

Received 22 August 1983 